\title{
PERANCANGAN EKSTRAKSI FITUR MOTIF SASIRANGAN MENGGUNAKAN ALGORITMA NAÏVE BAYES BERBASIS COLOR HISTOGRAM DAN GRAY LEVEL CO-OCCURRENCE MATRICES (GLCM)
}

\author{
Fakultas Teknologi Informasi \\ Universitas Islam Kalimantan Muhammad Arsyad Al Banjari Banjarmasin \\ Zayid Musiafa, S.Kom, M.Kom \\ zayidmusiafa.fti@gmail.com
}

\begin{abstract}
ABSTRAK
Sasirangan adalah kain adat suku Banjar di Kalimantan Selatan yang dibuat dengan teknik tusuk jelujur. Penelitian menggunakan uji algoritma Naive Bayes Klasifikasi terhadap citra kain sasirangan yang diekstrak dengan metode berbasis color histogram dan GLCM data terdiri dari 30 citra digital kain sasirangan terdiri dari 10 data citra motif Hiris Gagatas dengan label g class 0, 10 data citra motif Kulat Kurikit diberi label $k$ class 1, dan 10 data citra motif Absrak diberi label a class 2. Pengujian data menggunakan X-Validation dengan ketentuan Number Validaton uji 10 sampai dengan 2, type validasi yang diuji mulai dari Stratified Sampling, Shuffled Sampling dan Linier Sampling. Kesimpulan dari penelitian yang dilakukan diperoleh hasil accuracy Stratified Sampling Color Histogram dengan nilai validasi 5 miliki nilai tertinggi dibandingkan Shuffled Sampling dan Linier Sampling dengan accuracy 63.33\%. Hasil accuracy Stratified Sampling GLCM $0^{\circ}$, GLCM 45 , dan GLCMRata-rata dengan nilai validasi 3 miliki nilai tertinggi dengan accuracy 80.00\%. Sedangkan hasil accuracy Stratified Sampling GLCM 90 dengan nilai validasi 3 dan Accuracy Linier Sampling nilai validasi 10 miliki nilai tertinggi dengan accuracy 73.33\%. Hasil accuracy Stratified Sampling GLCM $135^{\circ}$ dengan nilai validasi 3 miliki accuracy $76.67 \%$.
\end{abstract}

Kata Kunci : Sasirangan, Naive Bayes, Klasifikasi, Color Histogram, Grey Level Coocurrence Matrix (GLCM)

\section{PENDAHULUAN}

Sasirangan adalah kain adat suku Banjar di Kalimantan Selatan yang dibuat dengan teknik tusuk jelujur. Sejak tahun 2007, industri sasirangan ditetapkan sebagai salah satu dari sepuluh komoditi/produk/jenis usaha (KPJU) unggulan Kalimantan Selatan. Berdasarkan ragam hiasnya, sasirangan memiliki bermacam-macam motif, motif yang telah dikreasikan sesuai permintaan pemesan ataupun kreasi dari pengrajin sendiri. Karena nilai budaya dan nilai seninya, maka sasirangan menjadi produk yang bernilai ekonomis tinggi di era modern ini. Namun, selain sebagai produk ekonomi, sasirangan memiliki karakteristik pada motifnya. Motif motif dan ragam hiasnya, yang lahir dan dibangun dari proses kognitif manusia yang diperoleh dari sekitarnya. Sekarang ini motif sasirangan beragam dan masih ada beberapa yang belum dikenal masyarakat. Hal inilah dianggap sebagai 
salah satu aspek yang menarik untuk diteliti menggunakan sains dan teknologi. Pada penelitian ini, mengadopsi tentang bagaimana pemrosesan citra dapat digunakan untuk mengenali fitur dari citra sasirangan. Istilah fitur dari motif sasirangan adalah menyatakan representasi suatu fungsi citra kain sasirangan yang digunakan dalam pemrosesan visual lebih lanjut. Ektraksi fitur dari citra sasirangan merupakan proses untuk mendapatkan ciri dari dari persepsi visualnya.

Salah satu cara untuk mengatasi hal tersebut dengan melakukan klasifikasi kain. Sebenarnya terdapat banyak algoritma yang dapat dipergunakan untuk klasifikasi berdasarkan motif. Namun belum diketahui manakah algoritma yang lebih akurat untuk proses klasifikasinya. Penerapan algoritma Naïve Bayes diharapkan juga sebagai model yang tepat untuk menangani masalah klasifikasi sasirangan.

\section{RUMUSAN MASALAH}

Dari latar belakang masalah di atas, dapat disimpulkan bahwa terdapat banyak algoritma yang dapat dipergunakan untuk klasifikasi berdasarkan motif. Namun belum diketahui manakah algoritma yang lebih akurat untuk proses klasifikasinya. Sedangkan pertanyaan penelitian (research questions) pada penelitian ini adalah: "Bagaimana akurasi algoritma Naive Bayes dengan menggukan fitur ekstraksi color histogram dan GLCM untuk klasifikasi motif sasirangan?"

\section{TUJUAN PENELITIAN}

Berdasarkan latar belakang dan rumusan masalah diatas, maka penelitian ini bertujuan untuk Tujuan penelitian ini yaitu :

1. Menerapkan algoritma Naïve Bayes pada proses klasifikasi motif sasirangan.

2. Mengukur kinerja klasifikasi motif sasirangan dengan naïve bayes.

\section{TARGET LUARAN DAN MANFAAT PENELITIAN}

Target luaran dalam pembuatan laporan penelitian ini diharapkan dapat memberikan kontribusi positif sebagai media mengenalkan potensi daerah secara universal. Target luaran wajib dan tambahan dalampembuatan penelitian ini adalah :

a. Publikasi ilmiah dalam jurnal lokal yang mempunyai ISSN atau jurnal nasional terakreditasi seperti jurnal Al 'Ulum Universitas Islam Kalimantan (UNISKA)

b. Proseding pada seminar ilmiah baik yang berskala lokal, regional maupun nasional.

c. Pengayaan bahan ajar/diktat.

Manfaat dari penelitian ini adalah

1. Manfaat praktis Algoritma Naïve Bayes dapat digunakan pada proses klasifikasi motif sasirangan.

2. Manfaat teoritis Diharapkan Naïve Bayes dapat menghasilkan kinerja yang maksimal pada proses klasifikasi motif sasirangan.

3. Manfaat kebijakan Klasifikasi motif 
sasirangan diharapkan dapat membantu

masyarakat atau pihak pihak terkait untuk mengenali motif kain sasirangan.

\section{METODE PENELITIAN}

\section{Pengumpulan Data}

Metode penelitian yang dilakukan adalah metode penelitian eksperimen, dengan tahapan penelitian seperti berikut:

1. Pengumpulan Data (Data Gathering)

Data primer yang diperoleh peneliti adalah data hasil foto sasirangan.

2. Pengolahan Awal Data (Data Preprocessing)

Merupakan tahap pengolahan awal data dalam mempersiapkan data yang telah diperoleh dari tahap pengumpulan data sebelumnya untuk dilakukan proses selanjutnya.

3. Model/Metode Yang Diusulkan (Proposed Model/Method)

Metode yang diusulkan adalah metode perbandingan tingkat akurasi dari masing-masing fitur yang diuji dengan Naïve klasifikasi.

4. Eksperimen dan Pengujian Metode (Method Test and Experiment)

Eksperimen dan pengujian metode merupakan perhitungan dan simulasi pengujian metode yang digunakan pada penelitian ini.

5. Evaluasi dan Validasi Hasil (Result

\section{Evaluation and Validation)}

Pada tahapan ini dilakukan evaluasi terhadap kesimpulan atau informasi yang diperoleh dari tiga kelas data yang diperoses hasil diperoleh yaitu tingkat akurasi.

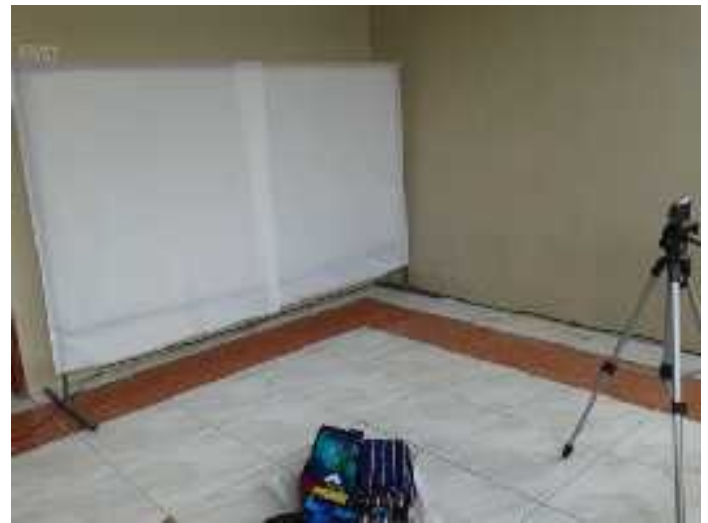

Gambar 1 Persiapan Pengumpulan Data

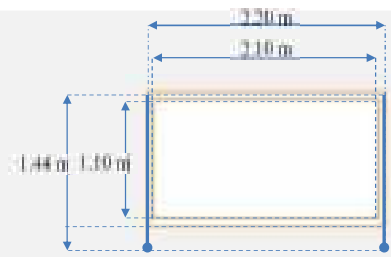

Gambar 2 Ukuran Frame Pigura Foto Kain

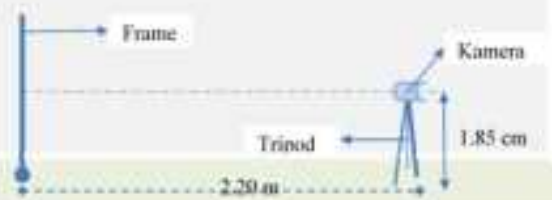

Gambar 3 Ukuran Jarak Frame Foto dengan Tripod/Kamera

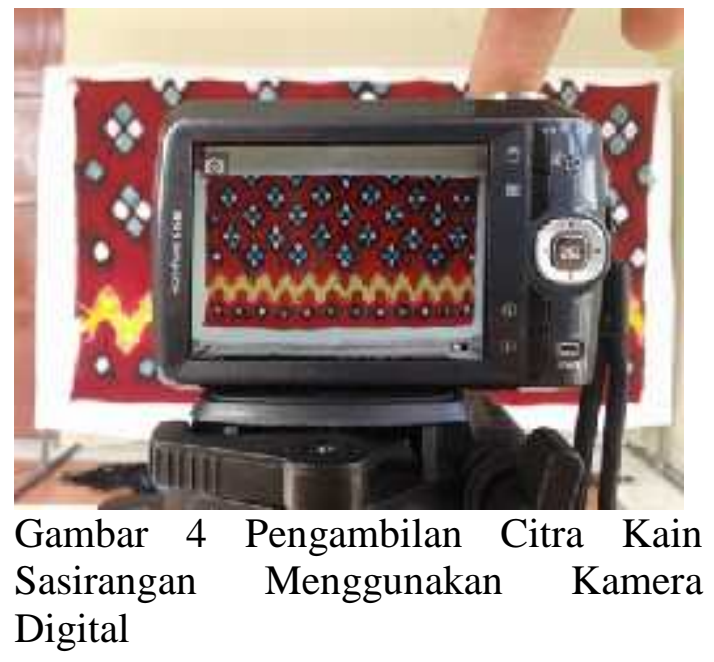

2. Pengolahan Awal Data (Data Preprocessing) 
Langkah-langkah yang dilakukan dalam tahap preprocessing :

1. Melakukan cropping bagian tepi frame foto tujuannya menghilangkan background foto sehingga hanya ada bagian kain sasirangan dengan ukuran $800 \times 444$ piksel siap sebagai dataset dan proses lanjutan yaitu ekstraksi.

2. Melakukan proses ekstraksi fitur bebasis color histogram dan Greey Level Coocurence Matrix (GLCM) Atribut yang digunakan dari masing-masing metode berbeda. Penggunaan atribut yang dipakai pada penelitian berdasarkan tabel dibawah ini hanya beberapa besaran yang diusulkan Haralick, Newsam dan Kammath (2005) hanya menggunakan lima besaran untuk GLCM, berupa angular second moment (ASM), contrast, inverse different moment (IDM), entropi, dan korelasi.

\section{Model/Metode Yang Diusulkan (Proposed Model/Method)}

Terdapat banyak algotrima yang dapat dipakai untuk klasifikasi namun belum diketahui algoritma manakah yang memiliki kinerja lebih akurat. Metode yang diusulkan adalah metode perbandingan tingkat akurasi hasil ekstraksi color histogram dengan GLCM yang diuji dengan Naïve Bayes klasifikasi.

\section{Eksperimen dan Pengujian Metode (Method Test and Experiment)}

Eksperimen dan pengujian metode merupakan perhitungan dan simulasi pengujian dalam menentukan class yang relevan dan jumlah citra yang relevan. Citra relevan disini berarti citra hasil pencarian yang memiliki kelas sama dengan citra query. Dengan demikian menghasilkan keluaran akurasi terbesar dari klasifikasi sasirangan. Pengujian pada tahap ini menggunakan tabel hasil ekstraksi color histogram dan GLCM digunakan sebagai model pada Tools Rapidminer.

\section{Evaluasi dan Validasi Hasil}

Analisa kebutuhan dilakukan untu mengetahui semua kebutuhan sistem, baik pada saat perancangan ataupun pada saat sistem diimplementasikan. Dengan mengetahui kebutuhan sistem maka proses pengembangan software dan implementasi dapat dikerjakan dengan lebih efisien.

Hardware yang diperlukan yakni kamera, jenis kamera digunakan penulis pada penelitian ini adalah kamera digital (saku) dengan lensa 33mm-96mm (Equivalent) 14MP.

Laptop yang digunakan untuk melakukan penelitian ini dengan spesifikasi Processor intel i5 1.7Ghz, VGA NVIDIA Geforce 820 2GB. RAM 4GB DDR3

Penerapan metode-metode yang akan digunakan diimplementasi dengan software MatLab 2010a dengan antar muka Graphical User Interface (GUI). Software matlab banyak digunakan untuk penelitian pattern recognition, voice recognition dan teori-teori lain, pembuatan aplikasi dapat dilakukan dengan cepat dengan bantuan fungsifungsi yang sudah tersedia. Pengujian data dan algoritma serta validasi menentukan akurasi menggunakan RapidMiner 5. Operating System yang digunakan Windows 764 bit.

\section{Eksperimen dan Pengujian Model/Metode}




\section{Ekstraksi Fitur Berbasis Histogram}

Ekstraksi fitur berbasis color histogram ini menganalisa berdasarkan 6 atribut yakni rerata intensitas $(\mathrm{Mu})$, Deviasi, Skewness, Energi, Entropi, Smoothness. Sistem ekstraksi fitur berbasis color histogram menampilkan analisis tekstur kain sasirangan dengan bahasa pemprograman untuk membuat aplikasi ini adalah MatLab 2010a.

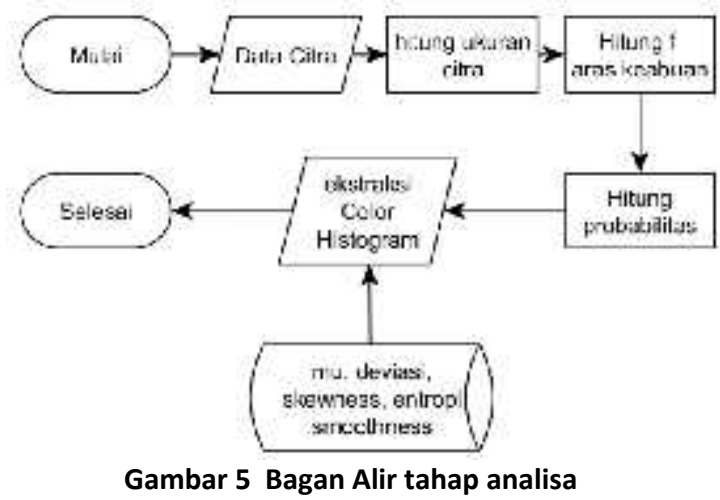

Hasil proses ekstraksi color histogram dengan 6 atribut dari 30 citra digital kain sasirangan terdiri dari 10 data citra motif Hiris Gagatas dengan label g menjadi class 0,10 data citra motif Kulat Kurikit diberi label $\mathrm{k}$ mejadi class 1 , dan 10 data citra motif Absrak diberi label a menjadi class 2. Hasil ekstraksi tersebut kemudian akan digunakan sebagai file repository pada aplikasi RapidMiner 5 untuk melanjutkan ke tahap selanjutnya.

\section{Ekstraksi Fitur GLCM}

Ekstraksi fitur GLCM ini menganalisa berdasarkan 5 atribut berupa angular second moment (ASM), contrast, inverse different moment (IDM), entropi, dan korelasi.

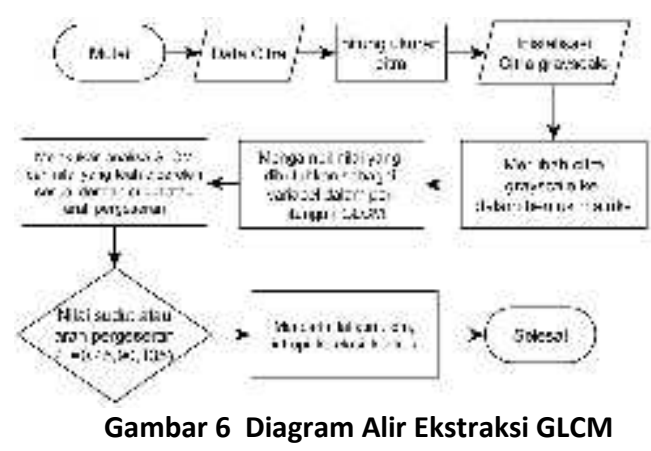

\section{Validasi Hasil}

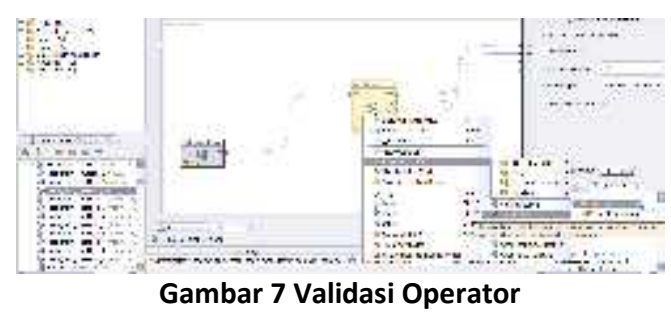

Membuat model menentukan jenis validasi dan algoritma naive bayes klasifikasi. Tahap selanjutnya adalah pengujian data menggunakan $\mathrm{X}$ Validation dengan ketentuan Number Validation uji 10 sampai dengan 2, type validasi yang diuji mulai dari Stratified Sampling, Shuffled Sampling dan Linier Sampling.

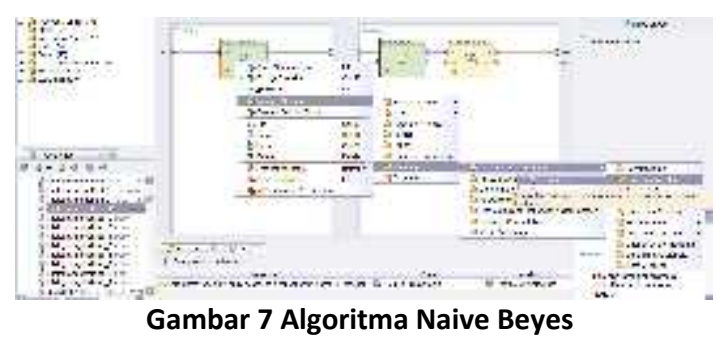

Skenario pengujian yang dilakukan adalah dengan mengunakan data training sebagai pelatihan terhadap sistem. Hasil klasifikasi data uji oleh sistem dibandingkan dengan klasifikasi data uji yang sesungguhnya. Analisis dilakukan dengan membandingkan antara data uji yang berhasil diklasifikasi dengan benar dengan semua data uji, maka didapatkan akurasi sistem klasifikasi motif tersebut berdasarkan tekstur kain. 


\section{PENUTUP}

\section{Kesimpulan}

Berdasarkan hasil penelitian dan pengukuran, dapat disimpulkan:

1. Accuracy Stratified Sampling Histogram dengan nilai validasi 5 miliki nilai tertinggi diantara kedua sampling dengan accuracy $63.33 \%$. Recall $\quad 70.00 \%$ pengambilan data yang berhasil dilakukan terhadap bagian data yang relevan dengan query motif abstrak, $50.00 \%$ pengambilan data yang berhasil dilakukan terhadap bagian data yang relevan dengan query motif gagatas, dan $70.00 \%$ pengambilan data yang berhasil dilakukan terhadap bagian data yang relevan dengan query motif kulat kurikit. Sedangkan bagian data yang di ambil sesuai dengan informasi yang dibutuhkan (precision) $77.78 \%$ untuk motif abstrak, $71.43 \%$ untuk motif gagatas, dan $50.00 \%$ untuk motif kulat kurikit.

2. Accuracy Stratified Sampling GLCM sudut $0^{\circ}$ dengan nilai validasi 3 miliki nilai tertinggi diantara kedua sampling dengan accuracy $80.00 \%$. Recall $80.00 \%$ pengambilan data yang berhasil dilakukan terhadap bagian data yang relevan dengan query motif abstrak, $70.00 \%$ pengambilan data yang berhasil dilakukan terhadap bagian data yang relevan dengan query motif gagatas, dan $90.00 \%$ pengambilan data yang berhasil dilakukan terhadap bagian data yang relevan dengan query motif kulat kurikit. Sedangkan $66.67 \%$ bagian data yang di ambil sesuai dengan informasi yang dibutuhkan (precision) untuk motif abstrak, $77,78 \%$ untuk motif gagatas, dan $100 \%$ untuk motif kulat kurikit.

3. Accuracy Stratified Sampling GLCM sudut $45^{\circ}$ dengan nilai validasi 3 miliki nilai tertinggi diantara kedua sampling dengan accuracy $80.00 \%$. Recall $80.00 \%$ pengambilan data yang berhasil dilakukan terhadap bagian data yang relevan dengan query motif abstrak, $70.00 \%$ pengambilan data yang berhasil dilakukan terhadap bagian data yang relevan dengan query motif gagatas, dan $\quad 90.00 \%$ pengambilan data yang berhasil dilakukan terhadap bagian data yang relevan dengan query motif kulat kurikit. Sedangkan $66.67 \%$ bagian data yang di ambil sesuai dengan informasi yang dibutuhkan (precision) untuk motif abstrak, 77,78\% untuk motif gagatas, dan $100 \%$ untuk motif kulat kurikit.

4. Accuracy Stratified Sampling GLCM sudut $90^{\circ}$ dengan nilai validasi 3 miliki nilai tertinggi dengan accuracy $73.33 \%$. Recall $80.00 \%$ pengambilan data yang berhasil dilakukan terhadap bagian data yang relevan dengan query motif abstrak, $70.00 \%$ pengambilan data yang berhasil dilakukan terhadap bagian data yang relevan dengan query motif gagatas, dan $\quad 70.00 \%$ pengambilan data yang berhasil dilakukan terhadap bagian data yang relevan dengan query motif kulat kurikit. Sedangkan $72.73 \%$ bagian data yang di ambil sesuai dengan informasi yang 
dibutuhkan (precision) untuk motif abstrak, 58,33\% untuk motif gagatas, dan $100 \%$ untuk motif kulat kurikit.

5. Accuracy Linier Sampling GLCM sudut $90^{\circ}$ dengan nilai validasi 10 miliki nilai accuracy 73.33\%. Recall 80.00\% pengambilan data yang berhasil dilakukan terhadap bagian data yang relevan dengan query motif abstrak, $50.00 \%$ pengambilan data yang berhasil dilakukan terhadap bagian data yang relevan dengan query motif gagatas, dan $\quad 90.00 \%$ pengambilan data yang berhasil dilakukan terhadap bagian data yang relevan dengan query motif kulat kurikit. Sedangkan $61.54 \%$ bagian data yang di ambil sesuai dengan informasi yang dibutuhkan (precision) untuk motif abstrak, $71,43 \%$ untuk motif gagatas, dan $90.00 \%$ untuk motif kulat kurikit.

6. Accuracy Stratified Sampling GLCM sudut $135^{\circ}$ dengan nilai validasi 3 miliki nilai tertinggi diantara kedua sampling dengan accuracy $76.67 \%$. Recall $80.00 \%$ pengambilan data yang berhasil dilakukan terhadap bagian data yang relevan dengan query motif abstrak, $60.00 \%$ pengambilan data yang berhasil dilakukan terhadap bagian data yang relevan dengan query motif gagatas, dan $90.00 \%$ pengambilan data yang berhasil dilakukan terhadap bagian data yang relevan dengan query motif kulat kurikit. Sedangkan $61.54 \%$ bagian data yang di ambil sesuai dengan informasi yang dibutuhkan (precision) untuk motif abstrak, 75,00\% untuk motif gagatas, dan $100.00 \%$ untuk motif kulat kurikit.

7. Accuracy Stratified Sampling GLCM Rata-Rata dengan nilai validasi 3 miliki nilai tertinggi diantara kedua sampling dengan accuracy $80.00 \%$. Recall $80.00 \%$ pengambilan data yang berhasil dilakukan terhadap bagian data yang relevan dengan query motif abstrak, $70.00 \%$ pengambilan data yang berhasil dilakukan terhadap bagian data yang relevan dengan query motif gagatas, dan $90.00 \%$ pengambilan data yang berhasil dilakukan terhadap bagian data yang relevan dengan query motif kulat kurikit. Sedangkan bagian data yang di ambil sesuai dengan informasi yang dibutuhkan (precision) $66.67 \%$ untuk motif abstrak, $77,78 \%$ untuk motif gagatas, dan $100.00 \%$ untuk motif kulat kurikit.

Dengan demikian metode GLCM lebih baik digunakan sebagai ekstraksi fitur dan memiliki akurasi tertinggi $80.00 \%$ dibandingkan dengan metode color histogram yang hanya mencapai accuracy $63.33 \%$. Nilai precision dengan metode GLCM diperoleh motif kulat kurikit mendominasi bernilai $100.00 \%$.

\section{Saran}

Agar penelitian ini bisa ditingkatkan, berikut ini adalah saran-saran yang diusulkan;

1. Menambahkan jumlah jenis motif kain sasirangan, menambah jumlah data yang lebih besar sehingga data pengukuran yang idapat lebih baik lagi. 
2. Menggunakan metode yang berbeda sehingga diperoleh algoritma yang terbaik untuk klasifikasi kain sasirangan.

\section{DAFTAR PUSTAKA}

[1] Rangkuti, A. Haris., 2014. Klasifikasi Motif Batik Berbasis Kemiripan Ciri Dengan Wavelet Transform Dan Fuzzy Neural Network, Jurnal ComTech Volume 5 Nomor 1, Nomor-01-June-2014 2087-1244, Universitas Bina Nusantara - Binus University, p. Journal_32_25, 2014-06.

[2] Miqdad, M., 2015. Penentuan Kualitas Kayu Kelapa Menggunakan Algoritma Naive Bayes Berdasarkan Tekstur pada Citra, Skripsi, Fakultas Ilmu Komputer UDINUS Semarang.

[3] Oktata, Dian, \& Pardede, D. L. Crispina., 2015. Perbandingan Kinerja Algoritma Decision Tree Dan Naive Bayes Dalam Prediksi Kebangkrutan, Jurnal Ilmiah Ilmu Komputer Program Studi Sistem Informasi, Universitas Gunadarma Depok.

[4] Saraswati, Ni Wayan Sumartini., 2011. Text Mining Dengan Metode Nä̈ve Bayes Classifier dan Support Vector Machines Untuk Sientiment Analyis, PROGRAM PASCASARJANA UNIVERSITAS UDAYANA DENPASAR.
[5] Destuardi, I. \& Surya, Sumpeno, 2009. Klasifikasi Emosi Untuk Teks Bahasa Indonesia Menggunakan Metode Naive Bayes, Seminar Nasional Pascasarjana Institut Teknologi Sepuluh Nopember.

[6] Yudistira, Dhimas Tantra., 2014. Penentuan Klasifikasi Status Gizi Orang Dewasa Dengan Algoritma Naive Bayes Classification Pada Puskesmas Jiken, Skripsi, Teknik Informatika Universitas Dian Nuswantoro Semarang.

[7] Yunanto, Wawan, Mochamad, Hariadi. Purnomo, Mauridhi Hery. 2014. Pemetaan Kecelakaan Lalu Lintas Berbasis Klasifikasi Naive Bayes Dengan Parameter Infrastruktur Jalan, Jurusan Teknik Elektro ITS, Surabaya.

[8] Syarif, Hisyam, 2014. Content Based Image Retrieval Berbasis Color Histogram Untuk Pengklasifikasian Ikan Koi Jenis Kohaku, Jurusan Teknik Informatika-S1, Fakultas Ilmu Komputer Semarang.

[9] Kurniawardhani, Arrie. Suciati, Nanik, Arieshanti, Isye. 2014. Klasifikasi Citra Batik Menggunakan Metode Ekstraksi Ciri Yang Invariant Terhadap Rotasi, JUTI ISSN : 1412-6389, vol. 12 Nomer 2, Institut Teknologi Sepuluh Nopember, Surabaya, pp. 48 - 60. 
[10] Kasim, Anita Ahmad, \& Harjoko, Agus. 2014. Klasifikasi Citra Batik Menggunakan Jaringan Syaraf Tiruan Berdasarkan Gray Level Co-Occurrence Matrices (GLCM), Jurusan Jurusan Ilmu Komputer dan Elektronika Instrumentasi Fakultas MIPA Universitas Gadjah Mada Yogyakarta Jurusan Teknik Elektro Fakultas Teknik Universitas Tadulako Palu,Sulawesi Tengah.

[11] Yodha, Johanes Widagdho \& Kurniawan, Achmad Wahid. 2014. Pengenalan Motif Batik Menggunakan Deteksi Tepi Canny Dan K-Nearest Neighbor," Techno.COM, vol. 13 No. 4, no. 1,2Program Studi Teknik Informatika, Fakultas Ilmu Komputer, Universitas Dian Nuswantoro Semarang, pp. 251262.

[12] Nugraha, Kristian Adi. Hapsari, Widi. Haryono, Nugroho Agus. 2014. Analisis Tekstur Pada Citra Motif Batik Untuk Klasifikasi Menggunakan K-Nn, Vol.2-Vol 10, No 2.

[13] Fajerin, Rafitri Riza. Ridok, Drs. Achmad. Ratnawati, Dian Eka,. 2013. Penentuan Motif Batik Berdasarkan Karakteristik Pemakai Menggunakan Gabungan Algoritma Naive Bayes Dan Algoritma Expectation Maximization (EM), Unversitas Brawijaya Malang.
[14] Mitchell, T.M., 2005. Machine learning, New York: McGrawHill.

[15] Woods, Rafael C. Gonzalez, and Richard E., 2002. Digital Image Processing Second Edition, Tom Robbins.

[16] AbdolVahan ehsanirad and Sharath Kumar Y. H, 2010. Leaf recognition for plant classification using GLCM and PCA methods, Oriental Journal of Computer Science \& Technology .

[17] Prasetyo, Eko., 2011. Pengolahan Citra Digital dan Aplikasinya Menggunakan Matlab, Yogyakarta: Andi.

[18] Kadir, Abdul \& Susanto, Adhi. 2013. Teori dan aplikasi pengolahan citra, Yogyakarta: Andi.

[19] Suryanto, 2008. Image Texture Feature Extraction Using GLCM Approach, International Journal of Scientific and Research Publications.

[20] Hasan, \& Ghassemian, Fardin Mirzapour, 2013. Using GLCM and Gabor filters for classification of PAN images, IEEE.

[21] Kacprzyk, Prof. Janusz, \& Jain, Prof. Lakhmi C., 2011. Florin Gorunescu, Data Mining: Concepts, Model and Techniques, vol. 12, Eds. Berlin,Jerman: Springer, pp. Chapter 6 
Classification Performance

Evaluation 319-322,

[22] M. H. Beale, M. T. Hagan dan H. B. Demuth, 2010. The MathWorks, Neural Network Toolbox: User's Guide ver.7, Penyunt.

[23] Confusion Matrix, [Online]. Available:

http://www2.cs.uregina.ca/ dbd/cs 831/notes/confusion_matrix/confu sion_matrix.html. [Diakses $18 \mathrm{Mei}$
2015].

[24] Kalimantan, Kantor PwBank Indonesia Wilayah, 2014. Rumah Sasirangan Rumah Kayu Di Tengah Kota, 2978-602-18981-78, Banjarmasin: KPwBank Indonesia Wilayah Kalimantan, pp. 20-21. 